\title{
COMPORTAMENTO DE CULTIAVRES DE VIDEIRA EM RELAÇÃO AO MÍLDIO
}

\author{
Andréa Ferreira da Costa ${ }^{1}$, Flávio Dessaune Tardin ${ }^{2}$, Hélcio Costa ${ }^{3}$, Drieli Aparecida Rossi ${ }^{4}$, Wellington \\ Ferreira Campos ${ }^{5}$, Anderson Ramos de Oliveira ${ }^{6}$, Alexandre Pio Viana ${ }^{7}$, Rosana Rodrigues ${ }^{7}$ e Messias \\ Gonzaga Pereira ${ }^{7}$
}

\begin{abstract}
${ }^{1}$ Doutora, Pesquisadora do Instituto Capixaba de pesquisa Assistência Técnica e Extensão Rural-Incaper, Rov. BR 262, KM 94, Domingos Martins, ES, Brasil, CEP:29278-000/Professora da Faculdade Venda Nova do Imigrante-FAVENI: andreacosta_2000@yahoo.com.br; ${ }^{2}$ Doutor, Pesquisador A, Núcleo de Recursos Genéticos e Obtenção de Cultivares, Embrapa Milho e Sorgo: flavio.tardin@embrapa.br; ${ }^{3}$ Doutor, pesquisador do Instituto Capixaba de Pesquisa Assistência Técnica e Extensão Rural-Incaper: helciocosta@incaper.es.gov.br; ${ }^{4}$ Doutora, professora da Faculdade Venda Nova do Imigrante-Faveni: drielirossi@ hotmail.com; ${ }^{5}$ Doutor, Professor da Universidade Federal dos Vales do Jequitinhonha e Mucuri, Instituto de Ciências Agrárias, Av. Vereador João Narciso, 1380, Unaí, Minas Gerais, Brasil, CEP 38610-000: wellingtonfcampos@ufvjm.edu.br.; ${ }^{6}$ Doutor, Pesquisador A, Núcleos Temáticos, Embrapa Semiárido: anderson.oliveira@embrapa.br; ${ }^{7}$ Doutor, Professor do Laboratório de Melhoramento Genético vegetal da Universidade Estadual do Norte Fluminense Darcy Ribeiro, Campos dos Goytacazes, Rio de Janeiro: messiasgpereira@gmail.com.
\end{abstract}

RESUMO- A viticultura é geradora de renda tanto em nível mundial como nacional. Entretanto, todas as regiões produtoras no Brasil são afetadas pelo míldio (Plasmopara viticola), doença que pode causar sérios danos a cultura. $\mathrm{O}$ objetivo do trabalho foi avaliar a resistência ao míldio de cultivares de uva introduzidas no norte fluminense. Para tanto foram avaliadas onze cultivares a saber, 'Rosalinda'; 'Itália'; 'Patrícia'; 'Kyoho'; 'Red Globe'; 'Roberta'; 'Rubi'; 'Niágara Rosada'; 'Isabel'; 'Moscatel de Hamburgo' e 'Romana'. As plantas foram conduzidas em sistema de "latada", no espaçamento 4,0 x 3,0 m, em delineamento experimental de blocos ao acaso, com três repetições e quatro plantas por parcela. Foram realizadas duas avaliações quanto ao nível da doença, uma referente a leitura dos sintomas, por três avaliadores que utilizaram uma escala de notas variando de 1 (resistente) a 5 (suscetível), e a segunda seguindo a escala proposta por Azevedo (1997). Foi feita análise de variância e teste de comparação de médias de Scott-Knott $(\mathrm{P}<0,05)$. Não houve diferença significativa considerando-se os dados gerados pelos avaliadores pela escala de 1 a 5, contudo pela escala proposta por Azevedo (1997) detectou-se diferenças significativas entre cultivares para reação ao míldio. Os genótipos testados diferiram quanto à resistência, sendo possível agrupá-los em duas categorias, a saber, como resistentes: 'Romana', 'Moscatel de Hamburgo', 'Isabel' e Niágara Rosada', e como suscetíveis: 'Rosalinda', 'Itália', 'Patrícia', 'Kyoho', 'Red Globe', 'Roberta' e 'Rubi'.

PALAVRAS-CHAVE: Plasmopara viticola. Resistência a doença. Vitis.

ABSTRACT- Viticulture generates income both at the global and national levels. However, in all Brazilian producing regions they are affected by mildew, a disease that can cause serious damage to the crop. The objective of the work was evaluated by a resistance to mildew of grape cultivars introduced in northern Rio de Janeiro. For both evaluated both eleven cultivars a saber, 'Rosalinda'; 'Italy'; 'Patrícia'; 'Kyoho'; 'Red Globe'; 'Roberta'; 'Ruby'; 'Pink Niagara'; 'Isabel'; 'Muscat of Hamburg' and 'Romana'. The plants were conducted in a "trellis" system, without spacing $4.0 \times 3.0 \mathrm{~m}$, in a randomized block design, with three replications and four plants per plot. Two evaluations of disease were performed, a reference to a reading of the symptoms, were found by three evaluators who used a scale of scores ranging from 1 (resistant) to 5 (susceptible), and a second following a scale proposed by Azevedo (1997). It was tested for variance and ScottKnott averages comparison test. It was not found the different meaning for the data generated by evaluators by scale of 1 to 5. The scale proposed by Azevedo (1997) detected an important difference between cultivars for mildew reaction. The genotypes tested differed as to their resistance, and it was possible to group them into two categories: 'Romana', 'Moscatel de 
Hamburg', 'Isabel' and Niagara Rosada ', and as susceptible:' Rosalinda ' Italy ',' Patrícia ',' Kyoho ',' Red Globe ',' Roberta 'and' Rubi '.

KEYWORD: Plasmopara vitícola. Disease Resistance. Vitis.

\section{INTRODUÇÃO}

A uva é uma das fruteiras economicamente mais importantes do mundo, sendo utilizada para a produção de vinhos, bebidas destiladas, consumo in natura, passas, suco, óleo de sementes de uva e processados para uso farmacêutico. No Brasil a uva é uma das principais frutas comercializadas (OLIVEIRA et al., 2017), e a produção brasileira já supera 1,5 milhões de toneladas, sendo que a metade é utilizada para consumo in natura e a outra metade para processamento (BUFFARA et al., 2014).

O crescimento sustentável e a competitividade da viticultura brasileira, tanto nas atuais como nas potenciais zonas de produção, dependem do uso de cultivares adaptadas cuja produção atenda a demandas do mercado. Segundo Almança, Lerin e Cavalcanti (2015), no Brasil, as regiões produtoras estão inseridas em locais com condições favoráveis às doenças. Dentre estas o míldio da videira, causado por Plasmopara viticola (Berk. \& Curt) Berl. \& de Toni, é doença de grande importância econômica em várias regiões do mundo. Os sintomas característicos são, manchas verde-clara, formadas na face superior das folhas, que evoluem para necroses de coloração castanho-avermelhadas, estas podem cobrir grande área do limbo foliar. Na face inferior das folhas, sob condições climáticas favoráveis, formam-se estruturas de frutificação de coloração esbranquiçada, os esporângios (ANGELOTTI et al., 2012; BUFFARA et al., 2014).

Assim, essas infecções podem causar perdas diretas, isto é, secamento de inflorescências, bagas e brotações; ou perdas indiretas, como infecções nas folhas com enfraquecimento e queda (ALMANÇA; LERIN; CAVALCANTI, 2015). Em adição, Angelotti et al. (2017) informam que as perdas podem chegar a $100 \%$ da produção.

O método mais utilizado para controlar o míldio é a aplicação de fungicidas (PRAJONGJAI et al., 2014; TOFFOLATTI et al., 2016). Entretanto estes adicionam custos extras a produção. Madden et al. (2000) informam que, os fungicidas utilizados podem levar à seleção de populações resistentes aos princípios ativos. Já Gessler et al. (2011) afirmam que pode ocorrer diversos impactos ao meio ambiente, além de haver a possilidade de danos na saúde do consumidor.

O cultivo de variedades que apresentam resistência ao mildio é considerado como a estratégia mais efetiva e econômica para controlar a doença (PAVLOUŠEK, 2012).

De acordo com Pommer et al. (2009) o município de Campos dos Goytacazes, no norte do estado do Rio de Janeiro, apresenta aptidão climática para produção de uvas, sendo possível obter colheita de uvas em mais de uma época durante o ano nessa região. Neste sentido, os fatores climáticos da região, associados à proximidade de grandes mercados consumidores como as cidades do Rio de Janeiro e Vitória, têm estimulado o investimento estadual em pesquisas que objetivem dar suporte aos produtores, para uma gradativa substituição de algumas áreas tradicionalmente cultivadas com cana-de-açúcar pelo cultivo de fruteiras. Entretanto, são raros os trabalhos de avaliação de genótipos de uva em relação ao míldio.

O estudo objetivou-se avaliar cultivares elites de videira introduzidas no norte do Rio de Janeiro, quanto à reação ao míldio em condições de ocorrência natural do patógeno. 


\section{MATERIAL E MÉTODOS}

O experimento foi conduzido em Campos dos Goytacazes, RJ, em área de convênio da Universidade Estadual do Norte Fluminense e o Colégio Agrícola Antônio Sarlo, onde cultivares de videira foram introduzidas e avaliadas quanto sua reação ao míldio em condições de ocorrência natural. As cultivares testadas foram: 'Rosalinda'; 'Itália'; 'Patrícia'; 'Kyoho'; 'Red Globe'; 'Roberta'; 'Rubi'; 'Niágara Rosada'; 'Isabel'; 'Moscatel de Hamburgo', e 'Romana'. As plantas foram conduzidas em sistema de "latada", com um sistema de ramificação principal ("braço") e suas ramificações secundárias, no espaçamento entre plantas de 4,0 x 3,0 m.

O delineamento experimental foi em blocos ao acaso com três repetições e quatro plantas por parcela. Duas avaliações foram realizadas no período compreendido entre os meses de maio e junho. Este período foi escolhido pois tem temperaturas amenas, e de acordo com Neto (2008), o desenvolvimento deste patógeno é favorecido pela alta umidade e por temperaturas amenas durante todo o ciclo da videira, neste sentido, Angelotti et al. (2012) informam que as temperaturas ideias para o desenvolvimento normal do patógeno variam entre a faixa de $18^{\circ} \mathrm{C} \mathrm{a}$ $25^{\circ} \mathrm{C}$.

A primeira avaliação consistiu na observação e leitura dos sintomas por parte de três avaliadores que utilizaram uma escala de notas variando de 1 (resistente) a 5 (suscetível). Num segundo critério, dez folhas de cada planta foram retiradas ao acaso de cada indivíduo, e levadas ao laboratório para imediata avaliação da severidade, seguindo-se a escala proposta por Azevedo (1997), que considera a porcentagem de área foliar lesionada.

Os dados foram submetidos a análise de variância univariada e as médias dos genótipos foram agrupadas pelo teste de Scott-Knott, a 5\% de significância, com auxílio do programa GENES (CRUZ, 2013).

\section{RESULTADOS E DISCUSSÃO}

Não houve diferença significativa considerando-se os dados gerados pelos avaliadores em condições de campo (escala de 1 a 5). No entanto, detectou-se diferença significativa entre cultivares para reação ao míldio avaliada pela escala proposta por Azevedo (1997), indicando que houve variabilidade genética para este caráter nos genótipos testados (TABELA 1). Isto demonstra a importância da definição do critério de avaliação adotado para quantificar a doença. Segundo Gaunt (1987), os métodos para avaliação de doenças devem ser escolhidos de forma criteriosa, isso para possibilitar um melhor grau de acurácia, precisão e repetibilidade das avaliações. No caso de doenças foliares, Sachs et al. (2011) explicam que a severidade é a variável mais utilizada, sendo que sua avaliação é, normalmente, feita por meio de análises visuais e, por conseguinte, as escalas diagramáticas tornam-se ferramentas fundamentais em tais estudos.

Tabela 1 - Análise de variância para reação ao míldio em onze cultivares de videira, em condições de ocorrência natural de $P$. viticola, determinada por escala diagramática considerando-se a porcentagem de área foliar afetada.

\begin{tabular}{lcccc}
\hline FV & GL & SQ & QM & F \\
\hline Blocos & 2 & 0,262042 & 0,131021 & $12,2206^{* *}$ \\
Tratamentos & 10 & 27,462097 & 2,74621 & \\
Resíduo & 20 & 4,4944 & 0,22472 & \\
\hline Coeficiente de Variação (\%) & & & 19,06 &
\end{tabular}


Se fosse considerado apenas o método baseado em escala de notas pela observação visual dos diferentes avaliadores, não teria sido registrada a existência de variabilidade para a reação ao míldio, já pela escala foi detectado variabilidade. Nunes e Alves (2012) explicam que as escalas diagramáticas são atualmente a principal ferramenta de avaliação da severidade de doenças. Buffara et al. (2014), em adição, explicam que as escalas são ferramentas valiosas para epidemiologia e controle de doenças de plantas, isto pelo fato de que podem ser usadas para padronizar a estimativa de severidade e reduzir as estimativas visuais subjetivas de severidade da doença, ou seja, são eficientes na avaliação das cultivares.

Quanto ao coeficiente de variação $(\mathrm{CV})$, foi considerado médio, isso conforme PimentelGomes (1985) que relata como sendo baixos coeficientes quando inferiores a 10\%; médios, quando de $10 \%$ a $20 \%$; altos, quando de $20 \%$ a $30 \%$, e muito altos, quando superiores a $30 \%$. Entretanto Zimmermann (2004) explica que, cada variável possui uma escala própria de coeficientes que está relacionada à sua variabilidade intrínseca, e que muitos autores têm procurado estabelecer tabelas associando os valores de CV aos conceitos: baixo, médio, alto e muito alto. Assim, para cada variável estudada uma tabela de limites pode ser construída com limites bem diversos uma das outras.

Outro aspecto que merece ser destacado foi o elevado índice de determinação genotípica, que correspondeu a $92 \%$ no presente estudo. Isto indica que, com as cultivares testadas, nas condições experimentais estabelecidas, a grande maioria das diferenças é devida a causas genéticas.

A análise pelo teste de Scott-Knott classificou as médias em dois grupos, com sete cultivares suscetíveis e quatro resistentes (TABELA 2).

Tabela 2 - Agrupamento das médias pelo teste de Scott-Knott para reação ao míldio em onze cultivares de videira, em condições de ocorrência natural de $P$. viticola, determinada por escala diagramática considerando-se a porcentagem de área foliar afetada.

\begin{tabular}{ll}
\multicolumn{1}{c}{ CULTIVARES } & MÉDIA $^{1 /}$ \\
\hline Rosalinda & $3,74 \mathrm{a}$ \\
\hline Itália & $3,44 \mathrm{a}$ \\
\hline Patrícia & $3,17 \mathrm{a}$ \\
\hline Kyoho & $3,15 \mathrm{a}$ \\
\hline Red Globe & $2,95 \mathrm{a}$ \\
\hline Roberta & $2,70 \mathrm{a}$ \\
\hline Rubi & $2,61 \mathrm{a}$ \\
\hline Niágara Rosada & $2,02 \mathrm{~b}$ \\
\hline Isabel & $1,53 \mathrm{~b}$ \\
\hline Moscatel de Hamburgo & $1,03 \mathrm{~b}$ \\
\hline Romana & $1,00 \mathrm{~b}$ \\
\hline
\end{tabular}

${ }^{1 /}$ Médias seguidas de mesma letra não diferem entre si pelo Teste de Scott-Knott a 5\% de probabilidade.

As cultivares Rosalinda, Itália, Patrícia, Kyoho, Red Globe, Roberta e Rubi, se mostraram suscetíveis por terem os maiores valores de severidade, ou seja, maiores porcentagens de área foliar lesionada. Neste grupo com exceção de Kyoho que é híbrida, todos os outros genótipos são variedades de $V$ vinífera (SILVA, 2006). Neste sentido Toffolatti et al. (2016) informam que, as principais variedades de $V$. vinifera cultivadas são geralmente muito suscetíveis a $P$. viticola, fato que explica a suscetibilidade dos genótipos. 
As cultivares Niágara Rosada, Isabel, Moscatel de Hamburgo e Romana se mostraram resistentes sob condições naturais de ocorrência da doença. A cultivar Niágara Rosada é oriunda do cruzamento de $V$. labrusca $\times$ V . vinífera, sendo, portanto, híbrida de videira americana. Já a Isabel é cultivar da espécie $V$. labrusca que é americana (PESSANHA, 2007) e a cultivar Romana também é híbrida (POMMER et al. 1997). De acordo com Sônego, Garrido e Grigoletti Júnior (2005) as cultivares de uvas americanas e híbridas são mais resistentes que $V$. vinifera. Entretanto, no grupo consta as cultivares Moscatel de Hamburgo que segundo Silva (2006) é cultivar da espécie $V$. vinífera, tida como mais suscetível.

\section{CONCLUSÃO}

Não houve diferença significativa considerando-se os dados gerados pelos avaliadores em condições de campo para avaliação da reação ao míldio utilizando escala de nota de 1 a 5 , já a escala proposta por Azevedo (1997), foi efetiva no presente trabalho. As cultivares testadas diferiram quanto à resistência, sendo possível agrupa-las em duas categorias, a saber, como resistentes: 'Romana', 'Moscatel de Hamburgo', 'Isabel' e Niágara Rosada', e como suscetíveis: 'Rosalinda', 'Itália', 'Patrícia', 'Kyoho', 'Red Globe', 'Roberta' e ‘Rubi'.

\section{REFERÊNCIAS}

ALMANÇA, M. A. K.; LERIN, S.; CAVALCANTI, F. R. Doenças da videira. Informe Agropecuário, v.36, n.289, 2015. Disponível em: <https://www.embrapa.br/uva-e-vinho/buscade-publicacoes/-/publicacao/1048834/doencas-da-videira> Acesso em: 28 abr. 2017.

ANGELOTTI, F.; GAVA, C.A.T.; BATISTA, D.C.; FERNANDES, J.M.C.; PAVAN, W. Sistema de Alerta e Previsão para Doenças da Videira. Ed. 1, Petrolina: EMBRAPA/MAPAEmpresa Brasileira de Pesquisa Agropecuária Embrapa Semiárido e Ministério da Agricultura, Pecuária e Abastecimento 2012. 36 p. ISSN 1808-9992. Disponível em:

<https://www.infoteca.cnptia.embrapa.br/bitstream/doc/954176/1/SDC251.pdf.> Acesso em: 13 fev. 2016.

ANGELOTTI, F. et al. Climate change and the occurrence of downy mildew in Brazilian grapevines. Pesquisa Agropecuária brasileira, Brasília, v.52, n.6, p.426-434, jun. 2017. Disponível em: < http://www.scielo.br/scielo.php?pid=S0100204X2017000600426\&script=sci_arttext.> Acesso em: 25 jun. 2017.

AZEVEDO, L. A.S. Manual de quantificação de doenças de plantas. 1997. 114p.

BUFFARA, R. S et al. Elaboration and validation of a diagrammatic scale to assess downy mildew severity in grapevine. Ciência Rural, Santa Maria, v.44, n.8, 2014. Disponível em: <http://www.scielo.br/scielo.php?script=sci_arttext\&pid=S0103-84782014000801384. > Acesso em: 25 jun. 2017. 
CRUZ, C.D. GENES - a software package for analysis in experimental statistics and quantitative genetics. Acta Scientiarum, v.35, n.3, p.271-276, 2013.

GAUNT, R. E. Measurement of disease and pathogens. In: TENG, P. S. (Ed.) Crop Loss Assessment and Pest Management, St. Paul: APS Press, p.6-18, 1987.

GARRIDO, L.R.; ANGELOTTI, F. Impacto potencial das mudanças climáticas sobre as doenças da videira no Brasil. In: GHINI, R. et al. (Ed.). Impactos das mudanças climáticas sobre doenças de importantes culturas no Brasil. Jaguariúna: Embrapa Meio Ambiente, 2011. p.331356. Disponível em: <https://www.embrapa.br/busca-de-publicacoes/-

/publicacao/929117/impacto-potencial-das-mudancas-climaticas-sobre-as-doencas-da-videira-nobrasil> Acesso em: 25 jun. 2017.

GESSLER, C.; PERTOT, I.; PERAZZOLLI, M. Plasmopara viticola: A review of knowledge on downy mildew of grapevine and effective disease management. Phytopathol. Mediterr., V.50, p. 3-44, 2011.

MADDEN, L.V.et al. Evaluation of a disease warning system for downy mildew of grapes. Plant Disease, v.84, p.549-554, 2000.

NETO, E. O Míldio da videira. Estação de Avisos Agrícolas do Algarve. Patacão, p.17, 2008. Disponível em:< http:// http://www.drapalg.minagricultura.pt/downloads/mediateca/inimigos_culturas/mod_prev_IC/RT_Mildiodavideira.pdf $>$. Acesso em:04 jun. 2017.

NUNES, C. C.; ALVES, S. A. M. Elaboração e validação de escala diagramática para quantificação da severidade de entomosporiose em folhas de pereira. Summa phytopathol. v.38, n.3, p.239-244, 2012.

OLIVEIRA. L. D. S.; MOURA, M. S. B.; LEÃO, P. C. S., SILVA, T. G. F.; SOUZA, L. S. B. Características agronômicas e sensibilidade ao rachamento de bagas de uvas sem sementes. Journal of Environmental Analysis and Progress, v.02, n.03 p.274-282, 2017.Disponível em: <http://ead.codai.ufrpe.br/index.php/JEAP/article/view/1451/1501>Acesso em: 23 jun. 2017.

PAVLOUŠEK, P. Evaluation of foliar resistance of grapevine genetic resources to downy mildew (Plasmopara viticola). Acta univ. agric. et silvic. Mendel. Brun. V.60, n.8, p.191-198, 2012.

PESSANHA, PATRÍCIA GOMES DE OLIVEIRA. Nutrientes minerais em folhas e bagas de genótipos de videira cultivados no norte fluminense. $77 \mathrm{p}$. Mestrado em genética e melhoramento de plantas. Centro de Ciências e Tecnologias Agropecuárias. Universidade estadual do Norte Fluminense Darcy Ribeiro, 2007.

PIMENTEL-GOMES, F. Curso de estatística experimental. São Paulo: ESALQ, 1985. 467 p.

POMMER, C. V. et al. Avaliação do clone híbrido a1105 de uvas brancas sem sementes sobre dois porta-enxertos. Bragantia, Campinas, v. 56, n. 1, p. 1997. Disponível em: 
<http://www.scielo.br/scielo.php?script=sci_arttext\&pid=S0006-87051997000100017> Acesso em: 23 jun. 2017.

POMMER, C. V. et al. Potencial climático para a produção de uvas em Campos dos Goytacazes, região norte fluminense. Revista Brasileira de Fruticultura, Jaboticabal, v. 31, n. 4, p. 10761083, 2009. Disponível em: <http://www.scielo.br/scielo.php?script=sci_arttext\&pid=S010029452009000400022 . > Acesso em: 23 jun. 2017.

PRAJONGJAI, T.; POOLSAWAT, O.; PORNBUNGKERD, P.; WONGKAEW, S.; TANTASAWAT, P.A. Evaluation of Grapevines for Resistance to Downy Mildew (Plasmopara viticola) under Laboratory and Field Conditions. S. Afr. J. Enol. Vitic., Vol. 35, No. 1, 2014.

SACHS, P. J. D.; NEVES, C. S. V. J.; CANTERI, M. G; SACHS, L. G. Escala diagramática para avaliação da severidade da mancha branca em milho. Summa phytopathol. v.37, n.4, p.202204, 2011. Disponível em: <http://www.scielo.br/pdf/sp/v37n4/a07v37n4.pdf. > Acesso em: 23 jun. 2017.

SILVA, F.C.C. Avaliação de características químicas dos frutos, diversidade genética e detecção de marcadores moleculares associados ao gene da apirenia, em variedades de videira. 86p. Mestrado em genética e melhoramento de plantas. Centro de Ciências e Tecnologias Agropecuárias. Universidade estadual do Norte Fluminense Darcy Ribeiro, 2006.

SÔNEGO, O.R.; GARRIDO, L.R.; GREGOLETTI JUNIOR, A. Principais doenças fúngicas da videira no Sul do Brasil. Circular técnica 56. 2005. 32p.

TOFFOLATTI S. L.et al. Evidence of resistance to the downy mildew agent Plasmopara viticola in the Georgian Vitis vinifera germplasm. Vitis, v.55, p.121-128, 2016.

ZIMMERMANN, F.J.P. Estatística aplicada à pesquisa agrícola. Embrapa Arroz e Feijão, 402p. 2004.

Recebido para publicação: 13 de junho de 2017

Aprovado: 25 de julho de 2017. 